\title{
Blast response of full-size concrete walls with chemically reactive enamel (CRE)-coated steel reinforcement"
}

\author{
Dong-ming YAN ${ }^{1}$, Hua-wei YIN ${ }^{\dagger 2}$, Cheng-lin WU ${ }^{3}$, Yan-long LI $^{4}$, Jason BAIRD ${ }^{5}$, Gen-da CHEN $\$ 6$ \\ ( ${ }^{1}$ School of Civil and Architectural Engineering, Zhejiang University, Hangzhou 310058, China) \\ $\left({ }^{2}\right.$ College of Civil Engineering, Hunan University, Changsha 410082, China) \\ ( ${ }^{3}$ Department of Civil, Architectural, and Environmental Engineering, Missouri University of Science and Technology, Rolla 654009, USA) \\ $\left({ }^{4}\right.$ State Key Laboratory Base of Eco-Hydraulic Engineering in Arid Area, Xi'an University of Technology, Xi'an 710048, China) \\ ( ${ }^{5}$ Rock Mechanics and Explosives, Missouri University of Science and Technology, Rolla 654009, USA) \\ $\left({ }^{6}\right.$ Center for Infrastructure Engineering Studies, Missouri University of Science and Technology, Rolla 654009, USA) \\ †E-mail: yhwzzy@163.com; gdchen@zju.edu.cn \\ Received July 1, 2016; Revision accepted Aug. 9, 2016; Crosschecked Aug. 18, 2016
}

\begin{abstract}
In this study, two full-size concrete walls were tested and analyzed to demonstrate the effectiveness of a chemically reactive enamel (CRE) coating in improving their mechanical behavior under blast loading: one with CRE-coated rebar and the other with uncoated rebar. Each wall was subjected in sequence to four explosive loads with equivalent 2, 4, 6-trinitrotoluene (TNT) charge weights of $1.82,4.54,13.6$, and $20.4 \mathrm{~kg}$. A finite element model of each wall under a close-in blast load was developed and validated with pressure and strain measurements, and used to predict rebar stresses and concrete surface strain distributions of the wall. The test results and visual inspections consistently indicated that, compared with the barrier wall with uncoated reinforcement, the wall with CRE-coated rebar has fewer concrete cracks on the front and back faces, more effective stress transfers from concrete to steel rebar, and stronger connections with its concrete base. The concrete surface strain distributions predicted by the model under various loading conditions are in good agreement with the crack patterns observed during the tests.
\end{abstract}

Key words: Chemically reactive enamel (CRE) coating, Blast loading, Crack pattern, Bond strength, Finite element model http://dx.doi.org/10.1631/jzus.A1600480

CLC number: TU375.2

\section{Introduction}

Reinforced concrete (RC) structures have been used worldwide in buildings and civil infrastructures due to local availability and inexpensive nature of concrete materials. With increasing concerns on the stability and durability of RC structures, more atten-

\footnotetext{
‡ Corresponding authors

* Project supported by the National Natural Science Foundation of China (Nos. 51379186 and 51522905), the Zhejiang Provincial Natural Science Foundation of China (No. LR15E090001), and the Leonard Wood Institute under Award (No. LWI61009), USA

(iD) ORCID: Dong-ming YAN, http://orcid.org/0000-0003-2522-3342; Gen-da CHEN, http://orcid.org/0000-0002-0658-4356

(C) Zhejiang University and Springer-Verlag Berlin Heidelberg 2016
}

tion has recently been paid to concrete-steel interface behaviors in the design and maintenance of constructed infrastructures. On the one hand, reducing the so-called interface transition zone (ITZ) effect can help protect the steel rebar from corrosion in a harsh environment. On the other, a smooth transition from concrete to steel rebar can greatly increase the steelconcrete bond strength and stiffness, thus enhancing the integrity of overall structures.

In the past two decades, effective approaches have been sought to improve the corrosion resistance of steel bar and the bond strength between steel bar and its surrounding concrete. To reduce the potential for corrosion in steel bar, materials such as calcium silicate compounds (Moon et al., 2007), elastomers 
(Seneviratne et al., 2000), quaternary thioarsenates (Yan et al., 2016a; 2016b), and geopolymers (Zhang et al., 2010) have been recently proposed for potential application to the surface of concrete structures for improved corrosion resistance in harsh environments. A few rebar coatings, which are regarded as a more cost-effective way to prevent the corrosion of rebar, have been developed, such as epoxy (Kobayashi and Takewaka, 1984), resin (Selvaraj et al., 2009), galvanizing metal (Kayali and Yeomans, 2000), and phosphate conversion (Jalili et al., 2009). However, when the bond strength between rebar and concrete is taken into consideration, it is found that the use of epoxy-coated rebar could reduce the bond strength by at least 20\% (Kobayashi and Takewaka, 1984); the use of galvanized steel has little influence on the bond strength (Kayali and Yeomans, 2000), and the use of $\mathrm{Zn}-\mathrm{Ca}$ phosphate coating could improve the bond strength by up to $74 \%$ (Jalili et al., 2009).

More recently, cement-modified enamel, which is termed as chemically reactive enamel (CRE), has been introduced for steel rod coating to increase the corrosion resistance of the steel rod and the bond strength between the steel rod and mortar (Day et al., 2006; Hackler et al., 2006). Since then, a series of systematic studies on deformed and smooth rebar have been conducted (Tang et al., 2012a; 2012b; 2013; Wu et al., 2012; 2013; Yan et al., 2012; 2016c). On the one hand, CRE-coated rebar has been demonstrated to have higher corrosion resistance than uncoated rebar in various applications (Tang et al., 2012a; 2012b; 2013). On the other, pullout tests with small specimens under static loading have proven that CRE coating can increase the bond strength of smooth rods in mortar by seven times (Yan et al., 2012) and the bond strength of deformed rebar in concrete by up to $32 \%$ (Wu et al., 2012). A smaller improvement in bond strength using CRE coating from the smooth rod to the deformed rebar was due to the dominant effect of concrete bearing on steel ribs of the deformed rebar so that the adhesion and friction become relatively small. Even so, the $32 \%$ increase in bond strength of the CRE-coated rebar in concrete is significant compared with at least $20 \%$ reduction in bond strength of epoxy-coated rebar (Kayali and Yeomans, 2000).

However, the bond behavior of CRE-coated rebar in concrete has not yet been investigated under dynamic loading. More importantly, the pullout specimens tested in the previous studies were all small in size. Thus, how the knowledge gained from small specimen testing is transferred to the system behavior in real-world structures is still unknown. In this paper, we investigate the dynamic properties of CRE-coated reinforced concrete with full scale barrier walls. The main objectives of this study are (1) to demonstrate the effectiveness of CRE coating in improving the serviceability and safety of RC barrier walls under blast loading, and (2) to verify the increase in bond strength of CRE-coated steel bar in concrete in real-world wall structures. To achieve these objectives, two full-size barrier walls with coated and uncoated rebar, respectively, were designed, fabricated, and tested under various charges. Then, they were also simulated with a finite element model that was calibrated with pressures and strain measurements and applied to predict rebar stresses and concrete surface strain distributions, and thus the crack pattern under various loading conditions.

There is an increasing terrorist threat worldwide. Car or truck bombs happen more frequently, and can have a devastating effect on essential facilities. To ensure the safety of military and civilian personnel, barrier walls are often placed in front of critical buildings and infrastructures. However, conventional $\mathrm{RC}$ walls fracture, spall, and throw considerable debris when hit by shockwaves and fragments from explosions, adding shrapnel to the devastating effect of the explosions. Rubble that is created when a conventional RC structure is destroyed is a significant part of both post-blast and post-disaster clean up, hampering recovery and consuming significant resources needed to secure a damaged site. RC walls that are better able to survive such blasts would provide continued force protection by maintaining structural and load-bearing integrity through reduced blast effects.

Most of the explosive failures associated with $\mathrm{RC}$ walls are related to the relatively weak bonds between concrete and reinforcement elements. Under blast loading, direct spalling occurs at multiple locations of an RC barrier wall (DDESB, 1990) due to the tension failure of concrete when subjected to the shock pressure of a blast wave. After losing their bond with steel reinforcement, pieces of the spalling concrete result in flying debris, causing significant human injuries and property damage. Specifically, the 
concrete elements under a close-in blast could accelerate before or immediately after concrete spalling. The accelerated motion of the elements charges the broken fragments to move at several hundred feet per second. With increased bond strengths, interior rebar may firmly hold most of the concrete fragments and mitigate the damage caused by the flying debris.

Stronger concrete-steel bonds, achieved using CRE-coated reinforcement as indicated in previous studies, allow an RC barrier wall to sustain greater explosive loads without losing structural integrity. The increased bond strength of CRE-coated rebar in concrete can potentially eliminate the weak point in the RC wall. Additionally, the use of CRE coating can greatly enhance the corrosion resistance of steel reinforcement, leading to a significantly improved long-term performance of barrier walls.

\section{Preparation and test of barrier walls}

\subsection{Material properties}

Type I Portland cement and Grade \#410 steel rebar with nominal yield strength of $410 \mathrm{MPa}$ were used to fabricate two RC barrier walls. One concrete wall was reinforced by steel bars that were coated with cement-modified enamel or mixed enamel. The mixed enamel used in this study consisted of $50 \%$ (in weight) commercial enamel and $50 \%$ calcium silicate that was taken directly from type I Portland cement (Tang et al., 2012a; 2012b; 2013). It was introduced to increase the bond strength between steel bar and concrete by increasing the surface roughness of coated steel bar for a mechanical bonding effect and by promoting the chemical reaction of the mixed enamel with concrete for a chemical bonding effect (Wu et al., 2012; Yan et al., 2012).

The enamels used in this study are silicate-based oxides that are deposited from slurries and fused at high temperature. The mixed enamel slurry was made by first adding $227 \mathrm{~kg}$ alkali borosilicate glass frits and $227 \mathrm{~kg}$ calcium silicate in Portland cement to $189.3 \mathrm{~kg}$ water, after mixing for $20 \mathrm{~min}$, then adding suspension agents (including $31.8 \mathrm{~kg}$ clay and $2.27 \mathrm{~kg}$ borax) and mixing for an additional $3.5 \mathrm{~h}$. The choice of alkali borosilicate glass frit was due to the fact that it contains $\mathrm{ZrO}_{2}$ which increases the alkaline resistance of enamels in harsh environments, and $\mathrm{NiO}$ and $\mathrm{CoO}$ which improve the adherence strength to steel bar (NRC, 1927).

Prior to the CRE coating process, all steel bars were sand-blasted and then cleansed with a cleansing solvent. After that, the clean steel bar was dipped in the mixed enamel slurry, heated for $2 \mathrm{~min}$ at $150{ }^{\circ} \mathrm{C}$ to drive off moisture, fired at $810{ }^{\circ} \mathrm{C}$ for $10 \mathrm{~min}$, and finally cooled to room temperature. The firing treatment at high temperature was used to melt the glass frit and chemically bond the mixed enamel to the steel bar.

In this study, six companying concrete cylinders were fabricated for each barrier wall at the time of concrete casting to obtain the 28-d compressive strength of concrete. The measured properties of materials are listed in Table 1.

Table 1 Materials properties

\begin{tabular}{clc}
\hline \multicolumn{2}{c}{ Parameter } & Value \\
\hline \multirow{2}{*}{ Concrete } & Compressive strength (MPa) & $44.0 \pm 1.4$ \\
& Modulus of elasticity (MPa) & $31.5 \pm 0.8$ \\
\hline \multirow{3}{*}{ Rebar } & Yield strength (MPa) & $490.0 \pm 2.2$ \\
& Ultimate strength (MPa) & $619.1 \pm 2.9$ \\
& Average strain at yield stress & 0.42 \\
& $(\%)$ & \\
\hline
\end{tabular}

Data are presented as mean \pm standard deviation

\subsection{Design and fabrication}

Concrete barrier walls that have been used to protect essential facilities and critical infrastructure from car-bomb attacks were considered as prototype structures in this study. Two full-size barrier walls as schematically shown in Fig. 1 were designed, each $1829 \mathrm{~mm}$ tall, $1219 \mathrm{~mm}$ wide, and $152.4 \mathrm{~mm}$ thick. The base of the barrier walls was a cuboid with $1219 \mathrm{~mm}$ long, $1219 \mathrm{~mm}$ wide, and $304.8 \mathrm{~mm}$ thick. Each specimen was reinforced with \#16 (about $16 \mathrm{~mm}$ in diameter) vertical deformed rebars and \#10 transverse stirrups, with the spacing being $152.4 \mathrm{~mm}$, as shown in Fig. 1. The concrete cover was $25.4 \mathrm{~mm}$ for all sides of the walls.

The full-size wall specimens were constructed with steel formworks and cured in the Highbay Structures Laboratory at Missouri University of Science and Technology, USA. After $28 \mathrm{~d}$ of curing, they were transported to a Fort Leonard Wood military 
training range and tested under blast loads at the test site. Prior to testing, each barrier wall was painted white for easy observation of surface cracks after blast tests. Twelve strain gauges were installed on vertical rebar. The locations of the gauges are shown in Fig. 1. It can be seen that strain gauges A1, B1, C1, $\mathrm{D} 1, \mathrm{E} 1$, and F1 are located at the mid-height of the wall while A2, B2, C2, D2, E2, and F2 were located at the very bottom of the wall. Strain gauges A1, B1, C1, D1, A2, B2, C2, and D2 were installed on the front side rebar while E1, F1, E2, and F2 were on the back side rebar of the barrier wall.

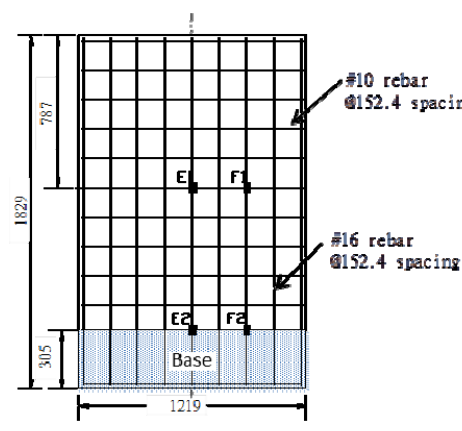

(a)

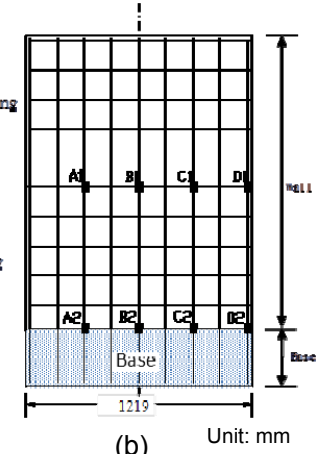

(b)
Fig. 1 Barrier wall details and strain gauge locations and designations: (a) back side; (b) front side

\subsection{Test set-up and procedure}

As indicated in Fig. 2, three pressure transducers were symmetrically deployed on the ground to measure the combined effect of blast waves propagated in air and reflected from the ground, each $5.49 \mathrm{~m}$ away from the center of a barrier wall and pointing directly at the explosive charge. One pressure transducer was located right in front of the wall (not shown in Fig. 2) and the other two were located on the two sides separately (Fig. 2).

Two 16-channel Synergy Box data recorders were employed to acquire strain and pressure data. One was employed along with a laptop to record the signals with a sampling rate of $20 \mathrm{kHz}$. Each barrier wall was repeatedly tested under $1.82,4.54$, and $13.6 \mathrm{~kg} \mathrm{2,4}$, 6 -trinitrotoluene (TNT) equivalent charges (Mays and Smith, 1995) which were placed at $1219 \mathrm{~mm}$ standoff distance from the center of charges to the center of the wall as illustrated in Fig. 2. Finally, the barrier wall was subjected to a demolition charge of $20.4 \mathrm{~kg}$ located right above the wall base at $609.6 \mathrm{~mm}$ standoff distance from the wall. The purpose of the demolition test was to understand the ultimate failure mode and demolish the tested wall for easy disposal. At the completion of each blast test, the barrier wall was thoroughly inspected and the surface crack patterns were marked and recorded for each blast.

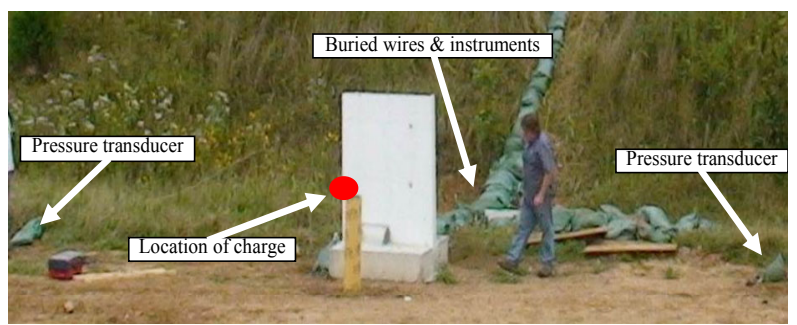

Fig. 2 Locations of charge and pressure transducers

\section{Test results and discussion}

The test results, which are an extension of those presented by Yan et al. (2011), are described as follows.

\subsection{Pressure measurements}

The measured pressures under 1.82, 4.54, and $13.6 \mathrm{~kg}$ charges are presented in Fig. 3. They are all dominated by positive pulses with various peak pressures and times of arrival as summarized in Table 2. It can be observed from Table 2 that the peak pressure increases and the time of arrival decreases with the charge weight partly due to increasing size of the charge. However, the time duration of the positive pulse is nearly equal for all cases.

\subsection{Surface cracks on barrier walls after blast tests}

To obtain a comprehensive understanding of the crack pattern of the two walls after being subjected to explosive loading, the cracks were mapped on the front and back faces of the tested barrier wall after each blast test and examined carefully. In general, cracks became visible when they were $0.02 \mathrm{~mm}$ or wider.

A more direct comparison between the two walls with uncoated and coated steel bars is made in Fig. 4. As can be seen from Fig. 4, generally, fewer cracks appeared on the upper portion of the walls, while a few more cracks appeared on the lower portion of the walls. This is likely attributed to the global flexural behavior of a cantilevered wall as the shock waves act 

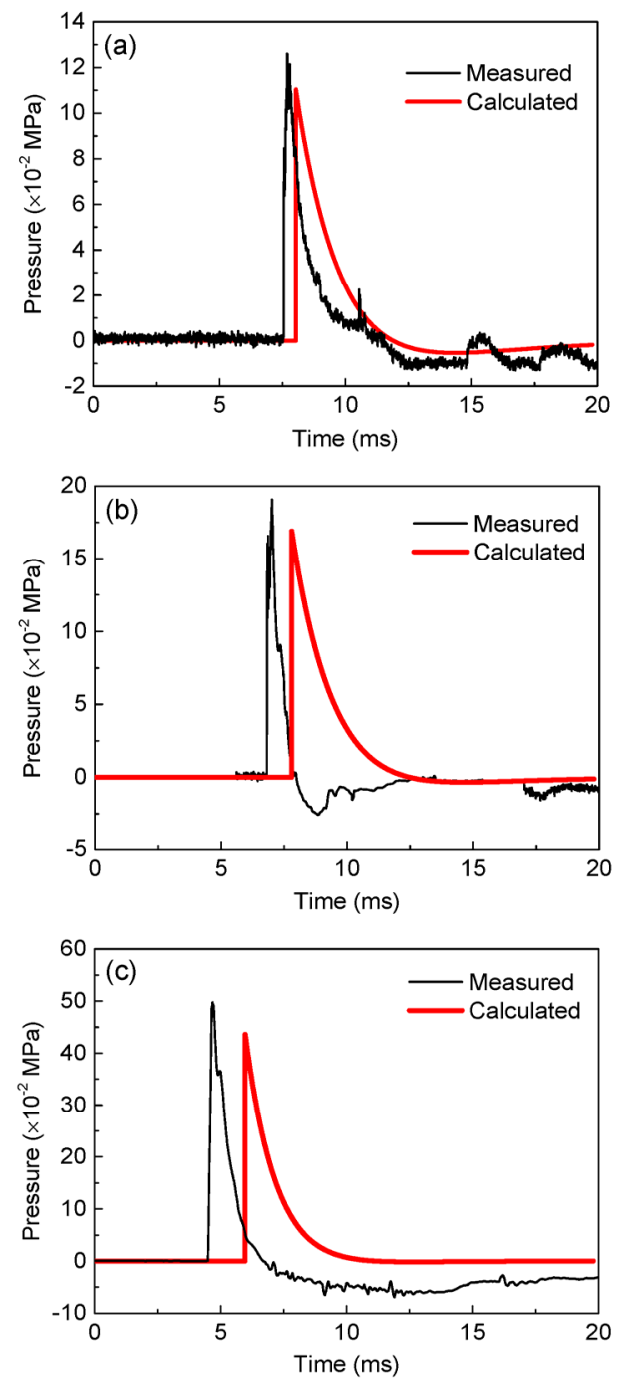

Fig. 3 Pressure time histories at the location of a pressure transducer under $1.82 \mathrm{~kg}$ (a), $4.54 \mathrm{~kg}$ (b), and $13.6 \mathrm{~kg}$ (c) charges

Table 2 Measured pressure pulses at the location of transducers

\begin{tabular}{ccc}
\hline $\begin{array}{c}\text { Charge weight } \\
(\mathrm{kg})\end{array}$ & $\begin{array}{c}\text { Peak pressure } \\
(\mathrm{MPa})\end{array}$ & $\begin{array}{c}\text { Time of arrival } \\
(\mathrm{ms})\end{array}$ \\
\hline 1.82 & 0.125 & 7.79 \\
4.54 & 0.172 & 6.98 \\
13.6 & 0.494 & 4.64 \\
\hline
\end{tabular}

on the front face of the wall. From Fig. 4a, it is found that more visible cracks appeared on the front face of the uncoated sample. The improved performance in the extent and pattern of cracks of the wall with CREcoated rebar mainly results from the adoption of CRE coating. When the wall was compressed by the shock front, the concrete on the front face locally suffered from bending as the stiffness of the front reinforcement grid suddenly changed, potentially causing concrete cracking. The adoption of CRE coating on steel bar provided a higher bonding strength between the steel bar and the surrounding concrete, and thus less stiffness changed around the shock front. This led to fewer cracks in the concrete, especially on the upper portion of the wall, and higher deformation in rebar, which will be discussed later. Similar to the front face, there were more visible cracks appearing on the back face of the wall with uncoated rebar as shown in Fig. 4b. As the bonding strength between CRE-coated steel reinforcement and concrete was significantly improved, the cracked concrete can still stick firmly to the steel reinforcement. As a result, no or fewer longitudinal cracks were formed along the CRE-coated steel bar. As such, the locally cracked concrete can behave better together with the steel bar to make the whole structure stiffer and stronger to resist the bending of structure as the impulse wave propagated through the rebar grid on the back face. This effect was demonstrated by fewer cracks on the back face of the barrier wall. Note that a smaller number of cracks indicate that there will be less

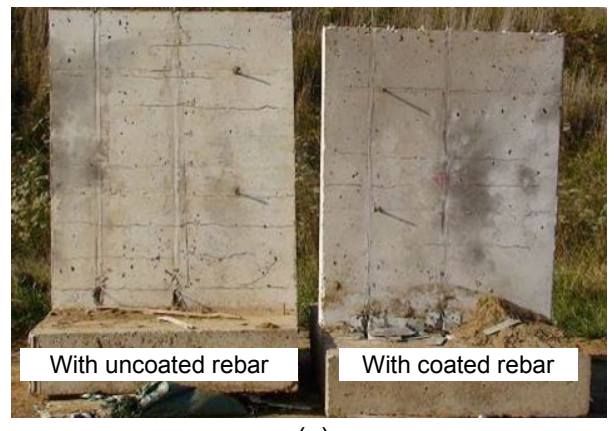

(a)

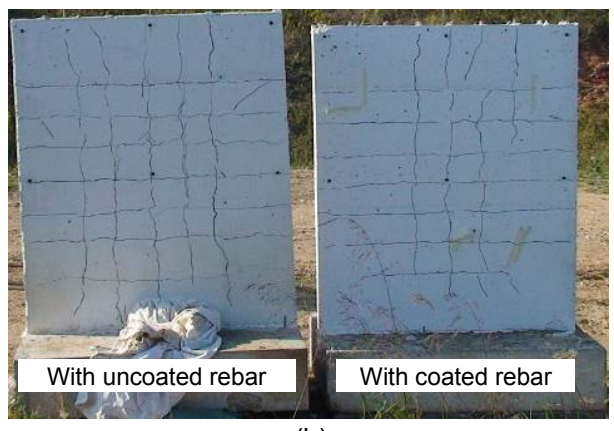

(b)

Fig. 4 Crack patterns and comparisons of two barrier walls after the first three tests: (a) front faces; (b) back faces 
likelihood for the invasion of corrosive substances, such as chloride and carbon dioxide, to steel bar and thus a longer serviceability of walls after having suffered explosive attacks.

After the explosion with a demolition charge of $20.4 \mathrm{~kg}$, the barrier wall with uncoated steel reinforcement was wiped out as can be seen from Fig. 5a, leaving behind the back half of the wall base. The steel cage in the front half of the wall base was scrapped. The damaged wall with CRE-coated steel reinforcement can be seen in Fig. 5b. The concrete of the wall was completely blown off. However, the longitudinal steel bars on the back side of the barrier wall stayed anchored into the wall base in a bent shape. By comparison with Fig. 5a, the remaining steel bar in Fig. 5b shows that the bond between steel bar and concrete was stronger due to the application of CRE coating. In addition, the steel bar cage in the front half of the wall base remained intact with some loose concrete pieces staying on the exposed steel bar, which was another indication of an improved bond strength between them.

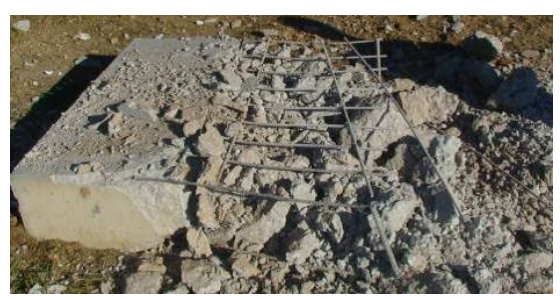

(a)

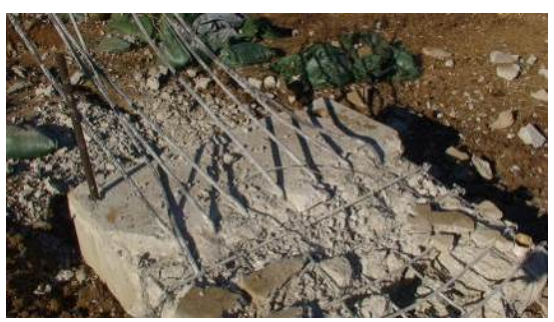

(b)

Fig. 5 Damaged walls after $20.4 \mathrm{~kg}$ TNT equivalent blast tests: (a) wall with uncoated steel reinforcement; (b) wall with CRE-coated steel reinforcement

\subsection{Strain measurements}

The locations of the 12 strain gauges on each barrier wall are illustrated in Fig. 1. For the barrier wall with uncoated steel bar, five strain gauges were damaged during the casting and transportation of the barrier wall or in the preparation (groove cutting) of the barrier wall test. For the wall with CRE-coated steel bar, four strain gauges were malfunctional during testing. The strain measurements under an explosion of $1.82 \mathrm{~kg}$ charge weight are shown in Figs. 6 and 7 for the walls with uncoated and CRE-coated steel bar, respectively. The locations of peaks on the strain-time histories are generally consistent (Figs. 6 and 7). For example, the locations of the first four peaks from B2 and $\mathrm{C} 2$ measurements are very close. This can partially ensure the reliability of the measured data. From Figs. 6 and 7, it can be seen that at the mid-height of the walls, the tension strains measured from the CRE-coated steel bar (B2 and C2) were remarkably higher than those from the corresponding uncoated steel bar. These results confirmed the conclusion drawn from the observations on crack patterns that the CRE-coated steel bar had higher bond strength with concrete and, when subjected to explosion, experienced much larger stress transferred from the surrounding concrete.
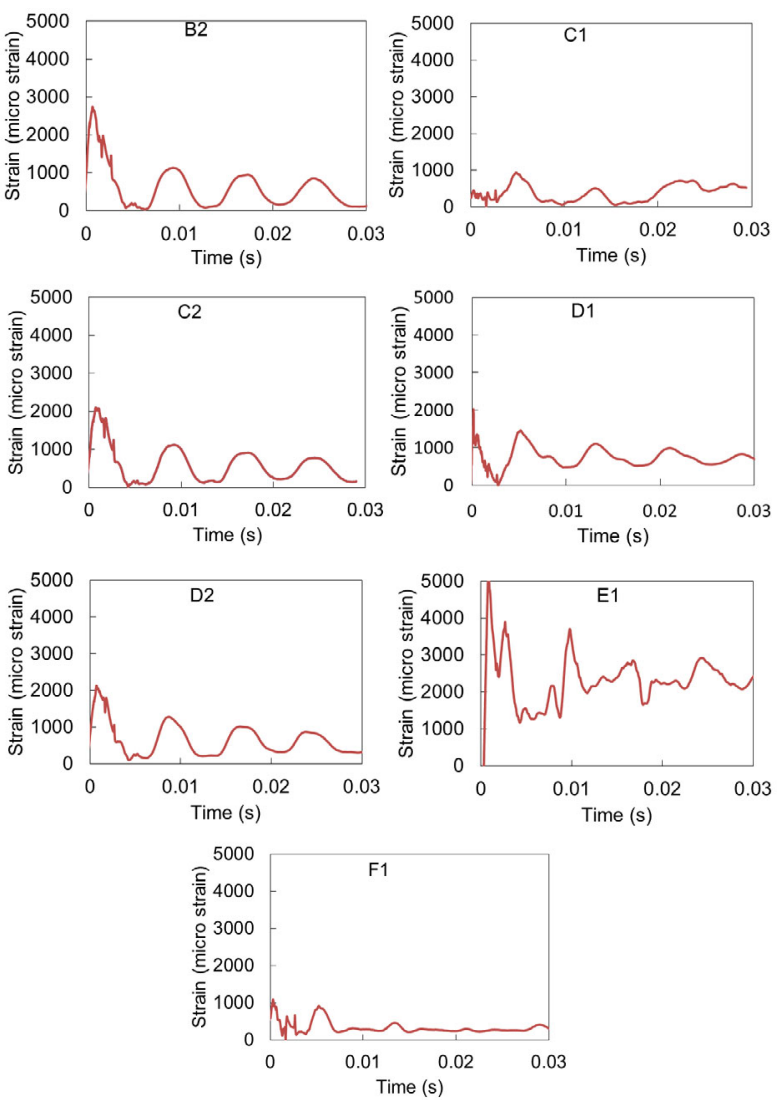

Fig. 6 Strain data from the barrier wall with uncoated rebar under a charge of $1.82 \mathrm{~kg}$ 

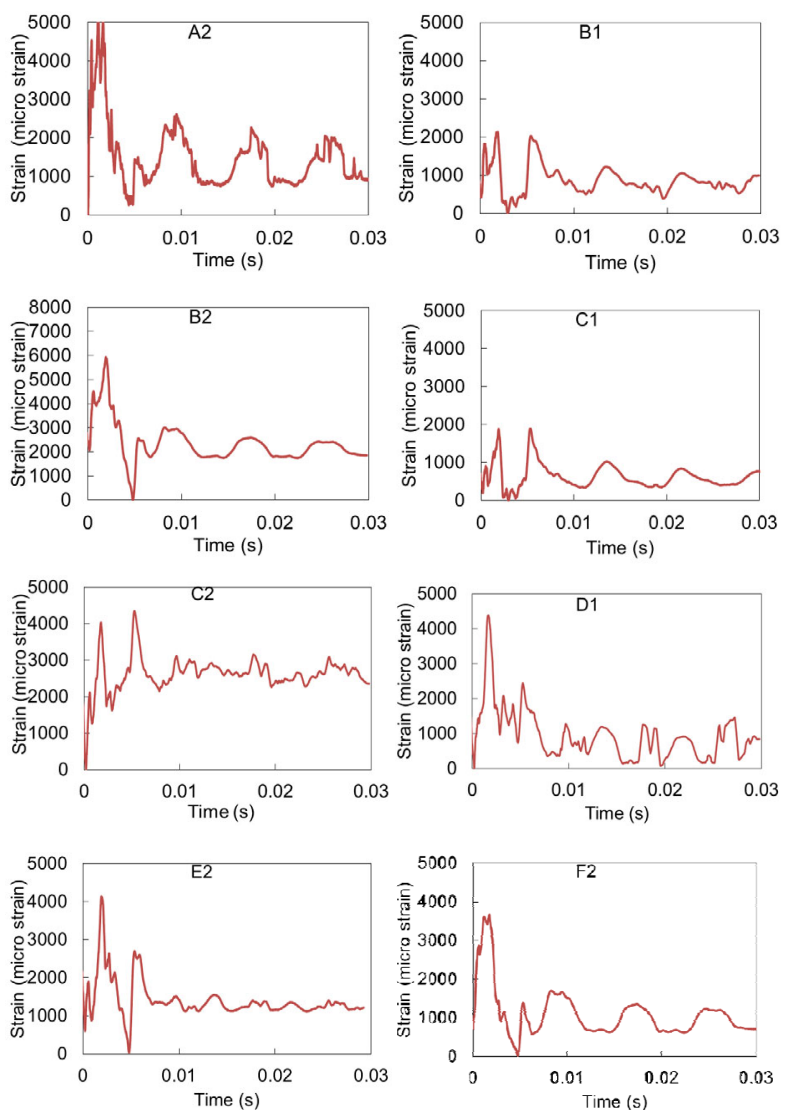

Fig. 7 Strain data from the barrier wall with CRE-coated rebar under a charge of $1.82 \mathrm{~kg}$

The strain measurements for the two walls during a charge of $13.6 \mathrm{~kg}$ are shown in Figs. 8 and 9. More strain gauges were damaged due to the previous blast loads and only four strain gauges worked correctly for each wall. A comparison between the strain measurement from coated and uncoated samples at location D1 is shown in Fig. 10. It can be seen that the locations of peak strain are still consistent. However, the strain in the wall with CRE-coated steel bar is much higher than that with uncoated rebar. This further ensures the conclusion that CRE coating could improve the bond strength of rebar with concrete and thus transfer more stress from the surrounding concrete during blast. Note that the strains measured under the charge of $13.6 \mathrm{~kg}$ were generally larger than that measured under the charge of $1.82 \mathrm{~kg}$. This is because after the foregone blast (such as the charge of $4.54 \mathrm{~kg}$ in this study), the strains of the rebar did not necessarily go back to zero. However, prior to the blast test with $13.6 \mathrm{~kg}$ charge, the strains of rebar were zeroed in the measurement system. In this case, the strain values in Figs. 8 and 9 are, virtually, relative increments of strain to the remaining values after the previous blast with $4.54 \mathrm{~kg}$ charge.
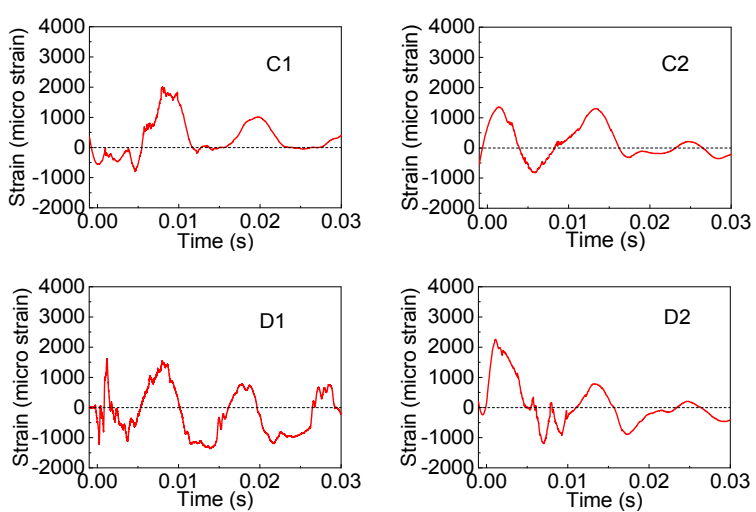

Fig. 8 Strain data from the barrier wall with uncoated rebar under a charge of $13.6 \mathrm{~kg}$
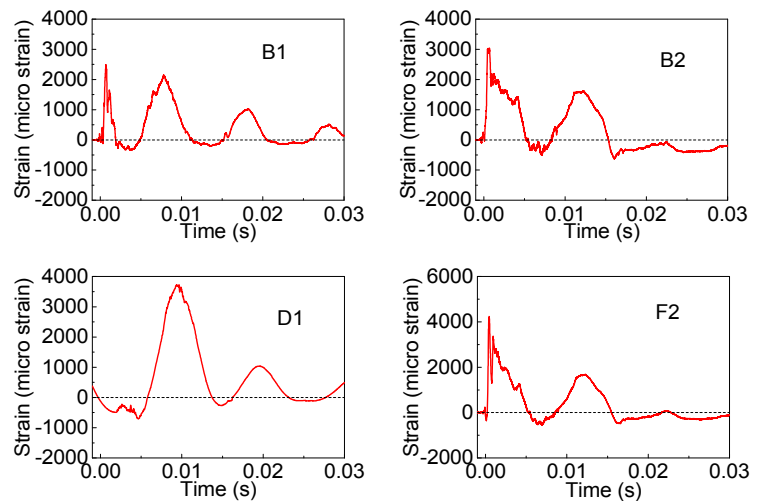

Fig. 9 Strain data from the barrier wall with CRE-coated rebar under a charge of $13.6 \mathrm{~kg}$

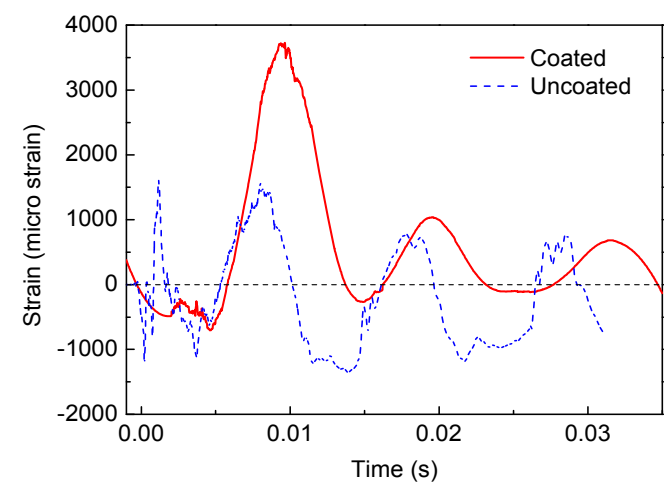

Fig. 10 Comparison between the CRE-coated and uncoated samples at location D1 under a charge of $13.6 \mathrm{~kg}$ 


\section{Numerical simulations}

\subsection{Finite element modelling}

The blast behavior of the two full-size RC walls can also be investigated with numerical simulations (Zhou et al., 2008; Coughlin et al., 2010). In this study, the finite element model of the right half of a barrier wall was developed with the LS-DYNA software using the explicit time step integration. The model was supported and constrained with two vertical springs and one rotational spring at the ground. The solid eight-node hexahedron element was adopted to model the concrete and the linear threenode Belytsckcho-Schwer beam element was employed to model the steel bar in both longitudinal and transverse directions. The base of the wall was discretized into cubic solid elements $50.8 \mathrm{~mm}$ in length and the barrier wall was discretized into cubic elements $25.4 \mathrm{~mm}$ in length. The meshed model is shown in Fig. 11. In all, there were 45930 elements and 51793 nodes in this model. To model the steel material, a bilinear stress-strain curve including strain rate effects was adopted (LSTC, 2015), where the strengths of the steel bar from preliminary tests were used. The continuous surface cap model (CSCM), an inherent material model in the LS-DYNA software, was adopted to model the concrete in the barrier walls. The CSCM is based on continuum damage mechanics in combination with plasticity theory, and it has been demonstrated that it has an elegant and robust theoretical basis and can well capture many important mechanical behaviors of concrete (Jiang et al., 2012; Jiang and Zhao, 2015). The material parameters, such as Young's modulus and Poisson's ratio, were automatically generated in LS-DYNA based on the target concrete compressive strengths. Parameters related to strain rate were adopted according to the recommended values from CEB (1993).

Perfect bond was assumed between the steel bar and its surrounding concrete. Note that the interfacial layer surrounding the coated steel bar consisted of a coating layer (100-180 $\mu \mathrm{m}$ in thickness) and interfacial translation zone (about $0.5 \mathrm{~mm}$ in thickness) in concrete (Mindness et al., 2002), as illustrated in Fig. 12. To simulate different bond strengths for CRE-coated and uncoated rebar, the interfacial layer surrounding the steel bar, assumed as $1.27 \mathrm{~mm}$ in thickness, was modeled with cubic eight-nodes solid elements. To simplify the simulation, the same size of elements was also assigned to specimens with uncoated samples. Based on experimental studies, Wu et al. (2012) reported that the coating factor (a ratio of the average bond strength of specimens with coated rebar to that with uncoated rebar) could lead to an improvement of $8 \%$ to $32 \%$ in bond strength. The concrete cover of the barrier wall is $25.4 \mathrm{~mm}$ and the compressive strength of concrete is $44.0 \mathrm{MPa}$, which are very close to the situation with the confined specimen in Series 1 of Wu et al. (2012). In this study, a coating factor of 1.20 was chosen to reflect the effect of CRE coating on the bond strength. In addition, it has also been proved that bond strength is directly proportional to the concrete compressive strength (Yang et al., 2016), and thus the compressive strength of concrete for the uncoated rebar is chosen as $35.0 \mathrm{MPa}$ and that of CRE-coated rebar as 44.0 MPa. Note that this is an approximation of the bond properties of coated or uncoated rebar in concrete. More studies should be directed to the failure

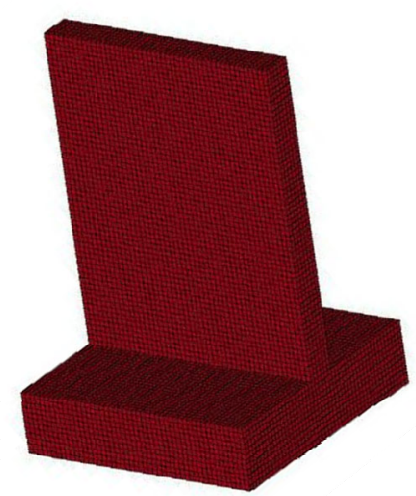

Fig. 11 Meshed finite element model of barrier wall

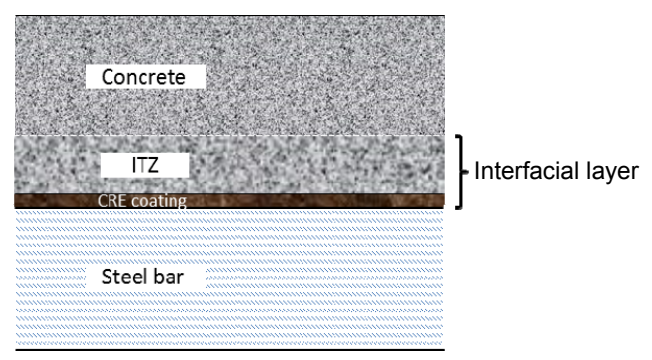

Fig. 12 Illustration of the interfacial layer 
mechanism of rebar-concrete interface at the microor meso-level to achieve a full understanding of the bond behavior and failure process of reinforced concrete with different types of coating.

The blast load corresponding to the experiment was applied to the wall model. It was implemented with the *LOAD_BLAST function in the LS-DYNA software. This function calculated the time histories of blast pressure for a set of surfaces based on the charts in TM 5-855-1/AFPAM 32-1147(I)/NAVFAC P-1080/DAHSCWEMAN-97 (Departments of the Army, Air Force, and Navy and the Defense Special Weapons Agency, 1997). The charge was represented as a hemisphere of hot and dense gas that initially has the density and specific internal energy of TNT high explosive. The center of charge and the equivalent TNT weight were used to represent the explosive load in the computer model corresponding to the test set-up. All faces of the wall model were assumed to receive the blast-induced pressures during explosion.

\subsection{Model calibration}

To accurately represent the test condition, the dimensions of the charges were taken into consideration in all the simulations. Under a close-in explosion, the finite element model of the barrier wall with CREcoated steel bar was calibrated with the blast-induced pressure in air and the strain of steel bar.

To compare with the measured pressure time histories, the reflected pressure from a spherical freeair burst of charges of $1.82,4.54$, and $13.6 \mathrm{~kg}$, which were placed $1219 \mathrm{~mm}$ above the ground, was simulated at the locations of two pressure transducers. The calculated pressure time histories from the finite element model being subjected to blast with different charge weights are compared with their corresponding measured data in Fig. 3. Fig. 3 shows that the calculated peak value is slightly lower and the positive pressure duration is longer than those of the measured pressure wave. The differences in arrival time were mainly ascribed to the different sizes of charges adopted during testing. The $1.82-\mathrm{kg}$ charge was a cylinder of $203.2 \mathrm{~mm}$ in diameter and $254.0 \mathrm{~mm}$ in length, the $4.54-\mathrm{kg}$ charge was a cube of $304.8 \mathrm{~mm}$ on each side, and the $13.6 \mathrm{~kg}$ charge was a rectangular cube of $406.4 \mathrm{~mm}$ in length, $304.8 \mathrm{~mm}$ in height, and $304.8 \mathrm{~mm}$ in depth.
The calculated strain-time histories are in general agreement with the measured values. For example, a simulated strain-time history at location B2 is presented in Fig. 13 under a charge of $1.82 \mathrm{~kg}$. Compared with the experimental time history, the first peak values and their corresponding locations of the simulated strains are consistent with those of the test data. However, note that the values and locations of the subsequent peaks clearly differ from each other, which may be because of a micro crack initiated in the wall. However, micro cracks were not considered in the finite element model.

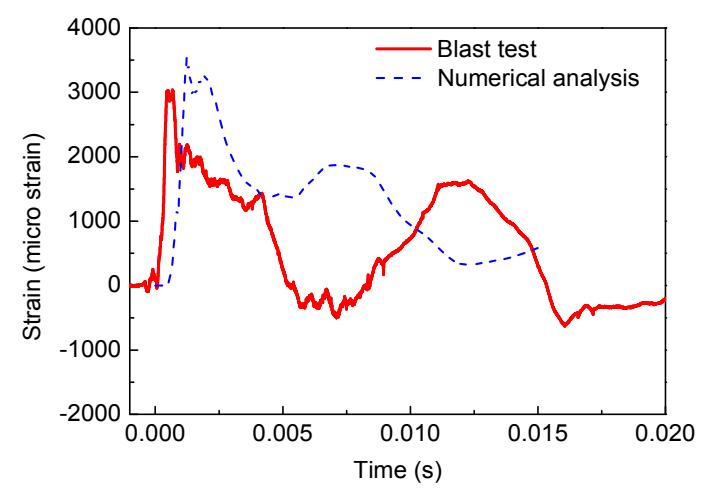

Fig. 13 Simulated strain-time history at location B2 of the wall with CRE-coated rebar under a charge of $1.82 \mathrm{~kg}$

The simulated effective plastic strain distributions at various time instances are presented in Fig. 14 for the right half of the barrier wall under a charge of $13.6 \mathrm{~kg}$. The high stress zones from the simulation are consistent with the crack patterns as shown in Fig. 4. Therefore, the cracks developed around the steel reinforcement correspond to the stress concentration effects.

\subsection{Analysis and discussion}

The calibrated model was used to predict the damage process of a barrier wall under blast loading and to conduct a sensitivity study on various parameters. Fig. 14 indicates that the effective plastic strain on the barrier wall achieves its maximum value at the center of the barrier wall and then the strain decays rapidly away from the center. When the weight of charge increases from $1.82 \mathrm{~kg}$ to $20.4 \mathrm{~kg}$, the calculated peak pressure at the center of the barrier wall increases rapidly from 5.07 MPa to $133.6 \mathrm{MPa}$. It can 
be observed from Fig. 14 that the effective plastic strain inside the wall reached its maximum in about $2 \mathrm{~ms}$, which is consistent with the strain measurements at B1, B2, and E2. The fringe levels represent the effective plastic strain in the model and can be used to evaluate damage (Mao et al., 2015).

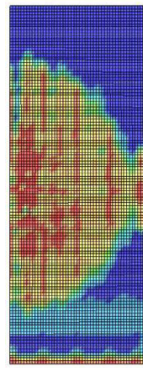

(a)

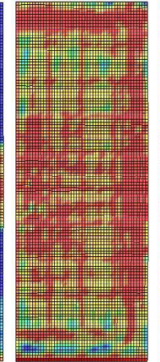

(b)

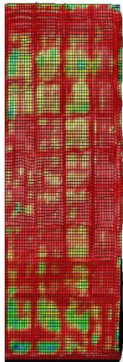

(c)

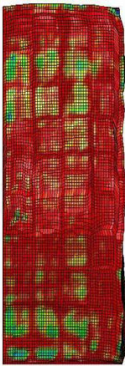

(d)
Fig. 14 Effective plastic strain distribution of the concrete wall with CRE-coated rebar under a charge of $13.6 \mathrm{~kg}$ (a) $0.51 \mathrm{~ms}$; (b) $0.67 \mathrm{~ms}$; (c) $1.99 \mathrm{~ms}$; (d) $4.50 \mathrm{~ms}$

The effect of bond strength on the wall behaviour was represented by the introduction of various strengths for the elements of the interfacial layer. Fig. 15 shows the rebar strain-time histories at location $\mathrm{B} 1$ of the wall with four selections of the interface material strengths: $30.0,35.0,40.0$, and 44.0 MPa. It can be seen from Fig. 15 that the difference in rebar stress is negligible when 30.0 and $35.0 \mathrm{MPa}$ are assigned to the interface materials. Both curves drop rapidly after the peak strain, which is an indication of debonding between the concrete and rebar. However, assigning 40.0 and $44.0 \mathrm{MPa}$ to the interface elements significantly delays the sudden strain drop and leads to larger energy dissipation during blasting. This means that the stronger bond of CRE-coated rebar in concrete can hold the damaged concrete surrounding the rebar and delay the separation of the broken concrete from the rebar.

Fig. 16 presents the size effect of vertical rebar on the strain-time history at location B1 of the wall with CRE-coated rebar under a charge of $13.6 \mathrm{~kg}$. It can be observed from Fig. 16 that the use of \#10 steel rebar gives the highest strain in steel rebar with the largest inelastic deformation due to blast loading. The strain in the \#16 rebar gradually reduces after the peak value likely due to ductile failure of the bond between the rebar and concrete, which is the case of the two full-size barrier walls tested. On the other hand, the use of \#22 rebar causes a sudden reduction to zero strain. This is likely due to the brittle failure of the bond between rebar and concrete, resulting in more stress in the concrete. These observations can be confirmed by the effective plastic strain distribution as shown in Fig. 17. The effective plastic strain of the concrete wall with $\# 22$ rebar is generally larger than that with \#10 rebar. Therefore, a relatively flexible design of barrier walls with small rebar is preferable so that the rebar and concrete can work together as the blast wave propagates through the wall. Figs. 15 and 16 also indicate that the rebar strains at location B1 under a charge of $13.6 \mathrm{~kg}$ were smaller than the ultimate strain of steel bar (approximately 10000 micro strain). Therefore, prior to the demolition test with a charge of $20.4 \mathrm{~kg}$, the RC barrier walls were mainly subjected to concrete cracking and rebar debonding.

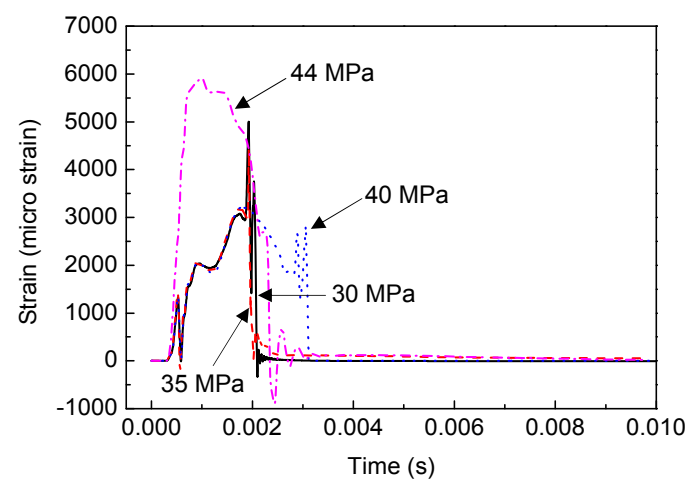

Fig. 15 Influence of interface material strength on the rebar strain-time history at location $B 1$ of the wall with CRE-coated rebar under a charge of $13.6 \mathrm{~kg}$

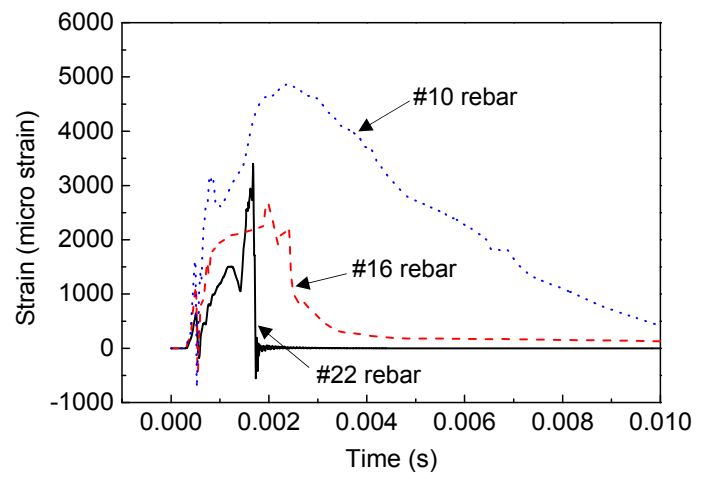

Fig. 16 Influence of rebar size on the steel strain-time histories at location B1 of the wall with CRE-coated rebar under a charge of $13.6 \mathrm{~kg}$ 


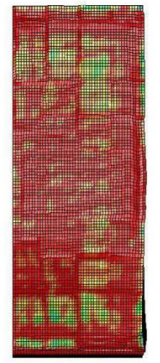

(a)

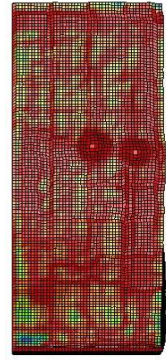

(b)

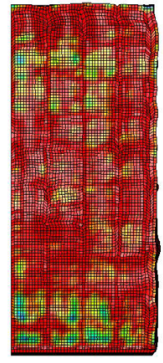

(c)
Fig. 17 Influence of rebar size on the effective plastic strain of the concrete wall with CRE-coated rebar under a charge of $13.6 \mathrm{~kg}$

(a) \#10 rebar; (b) \#16 rebar; (c) \#22 rebar

\section{Conclusions}

Based on the comparative study of two full-size, concrete barrier walls with CRE-coated and uncoated steel bars, respectively, the following conclusions can be drawn:

1. The crack patterns visually observed on the surfaces of the two walls under $1.82-\mathrm{kg}, 4.54-\mathrm{kg}$, and finally $13.6-\mathrm{kg}$ charges, clearly indicated that CRE coating firmly joined concrete to its nearby steel bar due to superior mechanical and chemical bonds of the mixed enamel with concrete, resulting in fewer rebarconcrete slippages and fewer cracks on the face of the wall. Therefore, the use of CRE coating in RC walls can enhance the serviceability of barrier walls under blast loads.

2. The strain measurements in steel rebar under $1.82-\mathrm{kg}$ and $13.6 \mathrm{-kg}$ charges verified that more stresses were transferred from concrete to the CREcoated rebar due to increased bond strengths between the CRE-coated rebar and concrete. Comparison of the ultimate failure modes of the two walls under a 20.4-kg charge further indicated the improved rebarconcrete bonding. Therefore, the use of CRE coating can improve the integrity and safety of barrier walls.

3. The finite element model of RC barrier walls under a close-in charge was calibrated with the measured pressure in air and the measured strains in rebar. The effect of CRE coating on the behavior of walls can be simulated by the introduction of a rebarconcrete interface layer with compressive strengths of 35.0 and 44.0 MPa for uncoated and CRE-coated rebars, respectively. The validated model can predict the concrete surface strain distribution with concentration around the rebar grid, and was in good agreement with the visually-observed crack pattern on the surface of walls. A flexible design of barrier walls with small rebar is desirable for the mitigation of blast-induced damage or concrete cracks.

\section{Acknowledgements}

The CRE-coated rebar were prepared by Pro-Perma Engineered Coatings, Inc., USA, with Mr. Michael L. KOENIGSTEIN as Managing Partner. The authors are grateful to Mr. Jason COX and Mr. Gary ABBOTT (Department of Civil, Architectural, and Environmental Engineering, Missouri University of Science and Technology, USA) for their assistances in preparing and field testing the two full-size barrier walls.

\section{References}

CEB (Comité Euro-International du Béton), 1993. CEB-FIP Model Code. Redwood Books, Wiltshire, UK.

Coughlin, A.M., Musselman, E.S., Schokker, A.J., et al., 2010. Behavior of portable fiber reinforced concrete vehicle barriers subject to blasts from contact charges. International Journal of Impact Engineering, 37(5):521529.

http://dx.doi.org/10.1016/j.ijimpeng.2009.11.004

Day, D.C., Weiss, C.A., Malone, P., et al., 2006. Innovative method of bonding Portland cement concrete to steel using a porcelain interface. Materials Science and Technology (MS\&T) Conference Proceedings, American Ceramic Society, Westerville, OH, USA.

DDESB (Department of Defense Explosives Safety Board), 1990. Structures to Resist the Effects of Accidental Explosions, TM 5-1300. DDESB, Alexandria, VA, USA.

Departments of the Army, Air Force, and Navy and the Defense Special Weapons Agency, 1997. Design and Analysis of Hardened Structures to Conventional Weapons Effects, TM 5-855-1/AFPAM 32-1147(I)/ NAVFAC P-1080/DAHSCWEMAN-97. Departments of the Army, Air Force, and Navy and the Defense Special Weapons Agency, Washington DC, USA.

Hackler, C., Koenigstein, M., Malone, P., 2006. The use of porcelain enamel coatings on reinforcing steel to enhance the bond to concrete and steel surfaces. Materials Science and Technology (MS\&T) Conference Proceedings, American Ceramic Society, Westerville, OH, USA.

Jalili, M.M., Moradian, S., Hosseinpour, D., 2009. The use of inorganic conversion coatings to enhance the corrosion resistance of reinforcement and the bond strength at the rebar/concrete. Construction and Building Materials, 23(1):233-238.

http://dx.doi.org/10.1016/j.conbuildmat.2007.12.011 
Jiang, H., Zhao, J., 2015. Calibration of the continuous surface cap model for concrete. Finite Elements in Analysis and Design, 97:1-19. http://dx.doi.org/10.1016/j.finel.2014.12.002

Jiang, H., Wang, X., He, S., 2012. Numerical simulation of impact tests on reinforced concrete beams. Materials and Design, 39:111-120. http://dx.doi.org/10.1016/j.matdes.2012.02.018

Kayali, O., Yeomans, S.R., 2000. Bond of ribbed galvanized reinforcing steel in concrete. Cement and Concrete Composites, 22(6):459-467. http://dx.doi.org/10.1016/S0958-9465(00)00049-4

Kobayashi, K., Takewaka, K., 1984. Experimental studies on epoxy coated reinforcing steel for corrosion protection. International Journal of Cement Composites and Lightweight Concrete, 6(2):99-116. http://dx.doi.org/10.1016/0262-5075(84)90039-3

LSTC (Livermore Software Technology Corporation), 2015. LS-DYNA Keyword User's Manual, R8.0. LSTC, USA.

Mao, L., Barnett, S.J., Tyas, A., et al., 2015. Response of small scale ultra high performance fibre reinforced concrete slabs to blast loading. Construction and Building Materials, 93:822-830.

http://dx.doi.org/10.1016/j.conbuildmat.2015.05.085

Mays, G.C., Smith, P.D., 1995. Blast Effects on BuildingsDesign of Buildings to Optimize Resistance to Blast Loading. Thomas Telford, London, UK.

Mindness, S., Young, J.F., Darwin, D., 2002. Concrete, 2nd Edition. Prentice Hall, USA

Moon, H.Y., Shin, D.G., Choi, D.S., 2007. Evaluation of the durability of mortar and concrete applied with inorganic coating material and surface treatment system. Construction and Building Materials, 21(2):362-369. http://dx.doi.org/10.1016/j.conbuildmat.2005.08.012

NRC (National Research Council), 1927. International Critical Tables, Vol. 2. McGraw-Hill, Washington DC, USA, p.116.

Selvaraj, R., Selvaraj, M., Iyer, S.V.K., 2009. Studies on the evaluation of the performance of organic coatings used for the prevention of corrosion of steel rebar in concrete structures. Progress in Organic Coatings, 64(4):454-459. http://dx.doi.org/10.1016/j.porgcoat.2008.08.005

Seneviratne, A.M.G., Sergi, G., Page, C.L., 2000. Performance characteristics of surface coatings applied to concrete for control of reinforcement corrosion. Construction and Building Materials, 14(1):55-59. http://dx.doi.org/10.1016/S0950-0618(00)00011-8

Tang, F., Chen, G., Brow, R.K., et al., 2012a. Corrosion resistance and mechanism of steel rebar coated with three types of enamel. Corrosion Science, 59:157-168. http://dx.doi.org/10.1016/j.corsci.2012.02.024

Tang, F., Chen, G., Brow, R.K., et al., 2012b. Microstructure and corrosion resistance of enamel coatings applied to smooth reinforcing steel. Construction and Building Materials, 35:376-384. http://dx.doi.org/10.1016/j.conbuildmat.2012.04.059
Tang, F., Chen, G., Volz, J.S., et al., 2013. Cement-modified enamel coating for enhanced corrosion resistance of steel reinforcing bars. Cement and Concrete Composites, 35(1): 171-180.

http://dx.doi.org/10.1016/j.cemconcomp.2012.08.009

Wu, C., Chen, G., Volz, J.S., et al., 2012. Local bond strength of vitreous enamel coated rebar to concrete. Construction and Building Materials, 35:428-439.

http://dx.doi.org/10.1016/j.conbuildmat.2012.04.067

Wu, C., Chen, G., Volz, J.S., et al., 2013. Global bond behavior of enamel-coated rebar in concrete beams with spliced reinforcement. Construction and Building Materials, 40: 793-801. http://dx.doi.org/10.1016/j.conbuildmat.2012.11.076

Yan, D., Chen, G., Baird, J., et al., 2011. Blast test of full-size wall barriers reinforced with enamel-coated steel rebar. Structures Congress, ASCE, Las Vegas, USA.

Yan, D., Reis, S., Tao, X., et al., 2012. Effect of chemically reactive enamel coating on bonding strength at steel/mortar interface. Construction and Building Materials, 28(1):512-518. http://dx.doi.org/10.1016/j.conbuildmat.2011.08.075

Yan, D., Hou, P., Liu, C., et al., 2016a. Effect of alkali cations on two-dimensional layer networks of two new quaternary thioarsenates (III) prepared by a facile surfactant-thermal method. Journal of Solid State Chemistry, 241:47-53.

http://dx.doi.org/10.1016/j.jssc.2016.05.035

Yan, D., Liu, C., Chai, W., et al., 2016b. Facile hydrazine-hydrothermal syntheses and characterizations of two new quaternary thioarsenates (III): twodimensional $\mathrm{SrAg}_{4} \mathrm{As}_{2} \mathrm{~S}_{6} \cdot 2 \mathrm{H}_{2} \mathrm{O}$ and one-dimensional $\mathrm{BaAgAsS}_{3}$. Chemistry-An Asian Journal, 11(12):18421848 .

http://dx.doi.org/10.1002/asia.201600381

Yan, D., Chen, S., Chen, G., et al., 2016c. Static and dynamic behavior of concrete slabs reinforced with chemically reactive enamel-coated steel bars and fibers. Journal of Zhejiang University-SCIENCE A (Applied Physics \& Engineering), 17(5):366-377. http://dx.doi.org/10.1631/jzus.A1500301

Yang, H., Lan, W., Qin, Y., et al., 2016. Evaluation of bond performance between deformed bars and recycled aggregate concrete after high temperatures exposure. Construction and Building Materials, 112:885-891. http://dx.doi.org/10.1016/j.conbuildmat.2016.02.220

Zhang, Z.H., Yao, X., Zhu, H.J., 2010. Potential application of geopolymers as protection coatings for marine concrete II: microstructure and anticorrosion mechanism. Applied Clay Science, 49(1-2):7-12. http://dx.doi.org/10.1016/j.clay.2010.04.024

Zhou, X.Q., Kuznetsov, V.A., Hao, H., et al., 2008. Numerical prediction of concrete slab response to blast loading. International Journal of Impact Engineering, 35(10): 1186-1200. http://dx.doi.org/10.1016/j.ijimpeng.2008.01.004 


\section{中文概要}

\section{题 目: 活性瓷釉涂层钢筋混凝土防护墙抗爆性能研究}

目 的：活性瓷釉涂层能够显著增强钢筋的防腐蚀能力, 同时能够明显提升钢筋与混凝土的粘结力。通过 对活性瓷釉涂层钢筋混凝土防护墙在冲击荷载 作用下的破坏特征进行试验和数值模拟, 为活性 瓷釉涂层技术在钢筋混凝土结构中的应用提供 理论基础。

创新点：1. 对活性瓷釉涂层钢筋混凝土防护墙进行爆炸荷 载作用下的破坏试验；2. 通过数值模拟，探究活 性瓷釉钢纤维对钢筋混凝土结构抗爆能力的影 响, 为结构设计提出建议。

方 法 1. 通过对活性瓷釉涂层钢筋防护墙进行爆炸试验 (图 2), 揭示活性瓷釉涂层钢筋混凝土结构的动
力破坏特征 (图 4 和 5); 2. 通过数值方法研究活 性瓷釉涂层对钢筋混凝土防护墙抗爆性能的影 响, 揭示在不同钢筋-混凝土粘结强度时钢筋混凝 土结构整体性的变化规律 (图 10、13 和 15); 3. 在 爆炸试验和数值分析基础上, 提出活性瓷釉涂层 钢筋混凝土结构抗爆设计建议（图 16）。

结 论: 1. 活性瓷釉涂层能够显著改善钢筋在混凝土结构 中的传力性能; 在爆炸荷载作用下, 涂层钢筋混 凝土结构的破坏程度明显减轻。2. 活性瓷釉涂层 能够显著改善钢筋混凝土结构的变形特性, 并显 著增强其耗能能力。3. 在采用活性瓷釉涂层进行 抗爆设计时, 采用直径较小的钢筋可提高结构的 吸能能力。

关键词：活性瓷釉涂层; 爆炸荷载; 破坏模式; 粘结力; 有限元模型 